\title{
Morphological Transformation and Photophysical Properties of Polyfluorene-Based Luminescent Rod-Coil Block Copolymers
}

\author{
Yang-Yen Yu ${ }^{1,2}$ and Chun-Yen Huang ${ }^{1}$ \\ ${ }^{1}$ Department of Materials Engineering, Ming Chi University of Technology, No. 84, Gongzhuan Road, Taishan District, \\ New Taipei City 24301, Taiwan \\ ${ }^{2}$ Center for Thin Film Technologies and Applications, Ming Chi University of Technology, 84 Gunjuan Road, Taishan, \\ New Taipei City 24301, Taiwan \\ Correspondence should be addressed to Yang-Yen Yu; yyyu@mail.mcut.edu.tw
}

Received 18 July 2016; Accepted 19 September 2016

Academic Editor: Antonios Kelarakis

Copyright ( 2016 Y.-Y. Yu and C.-Y. Huang. This is an open access article distributed under the Creative Commons Attribution License, which permits unrestricted use, distribution, and reproduction in any medium, provided the original work is properly cited.

\begin{abstract}
The morphologies, synthesis, and photophysical characterizations of poly[2,7-(9,9-dihexylfluorene)]-block-poly(2-(diethylamino)ethylmethacrylate) using amphiphilic rod-coil (PF- $b$-PDEAEMA) were demonstrated. The aggregation morphologies of $\mathrm{PF}_{13}$ $b$-PDEAEMA ${ }_{100}$ were manipulated by tuning the selectivity of mixed THF/methanol solvents with methanol contents ranging from 0 to $90 \mathrm{vol} \%$. The morphological transformation of $\mathrm{PF}_{13}-b$-PDEAEMA ${ }_{100}$ caused significant changes in its photophysical properties, including absorption, fluorescence spectra, and fluorescence quenching. Moreover, the thermal stability of $\mathrm{PF}_{13}-b-\mathrm{PDEAEMA}_{100}$ was investigated by varying the annealing temperature. The results of the present study suggest that the solvent selectivity influences the photophysical properties and aggregation morphologies of rod-coil block copolymers in solid and solution states.
\end{abstract}

\section{Introduction}

The potential of self-assembling amphiphilic rod-coil block copolymers in developing polymeric materials with novel supramolecular nanostructures and tunable physical properties has been demonstrated [1-4]. Such copolymers, which comprise mutually repulsive hydrophobic rod-like and hydrophilic coil-like segments, exhibit various nanoscale aggregation morphologies, such as spherical, lamellar, cylindrical, and worm-like structures [5-8]. The physical and optical properties and aggregation morphologies of rod-coil block copolymers can be manipulated by employing various driving forces, including relative block length, block polarity, mixed solvent selectivity, and temperature. Recently, block rod-coil copolymers have been investigated for many potential applications, such as in realizing drug diversity and in sensing [9-11], owing to their useful properties and morphological transformation.

In particular, block rod-coil copolymers containing semiconducting $\pi$-conjugated rods are considered promising candidates for low-cost, large-area, and flexible optoelectronic applications [12-16]. Conjugated rod-coil block copolymers exhibit unusual photophysical characteristics and may serve as novel optoelectronic materials. For example, Jenekhe and Chen demonstrated that poly(phenylquinoline)$b$-poly(styrene), a rod-coil copolymer, which showed an unusual honeycomb morphology, enhanced the solubility of fullerenes, such as $\mathrm{C}_{60}$ and $\mathrm{C}_{70}$, by encapsulating the fullerenes in the block conjugated copolymer aggregates [16].

Polyfluorene $(\mathrm{PF})$ derivatives are high-performance blue light-emitting materials used in polymeric light-emitting diodes because they have a high fluorescence quantum yield and strong thermal and chemical stability [10,17]. Several research groups have reported rod-coil block copolymers that are based on fluorene segments [18-21]. Rigid fluorene segments with flexible coil chains can be incorporated to not only manipulate the photophysical properties and aggregation morphologies of fluorene-based block copolymers but also increase the solubility of fluorene-based block copolymers in hydrophilic solvents, further improving processability. The potential biological applications, such as $\mathrm{pH}$ and DNA sensing, of block rod-coil copolymers with PF as rods and 


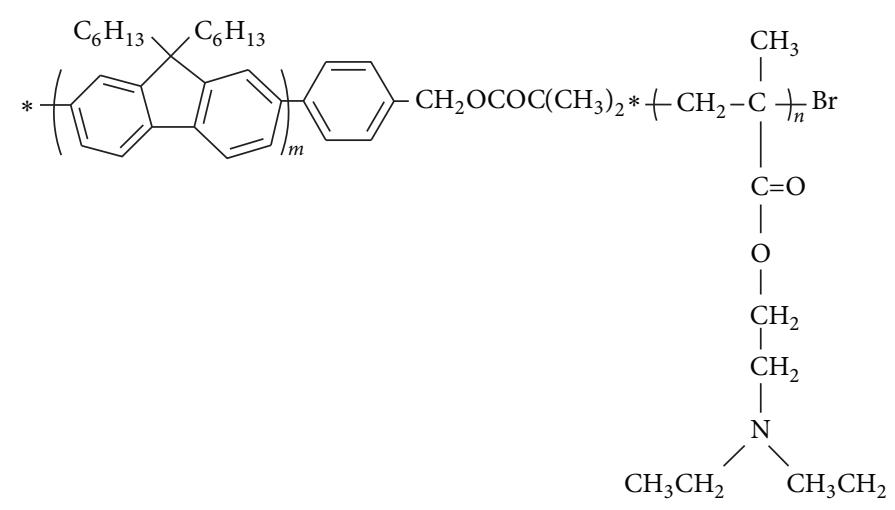

FIGURE 1: Chemical structure of rod-coil di-block PF- $b$-PDEAEMA.

poly(2-(dimethylamino)ethylmethacrylate) (PDMAEMA) as coils have been reported $[9,22]$; the highly hydrophilic PDMAEMA forms an ionic state with anions. However, the effect of the morphological transformation of di-block rodcoil copolymers composed of PF and PDMAEMA on their optoelectronic characteristics in solution and solid states has not been fully explored yet.

In this study, we demonstrated the synthesis, aggregation morphologies, and photophysical properties of amphiphilic poly[2,7-(9,9-dihexylfluorene)]-block-poly[2-(diethylamino)ethylmethacrylate] (PF- $b$-PDEAEMA) rod-coil diblock copolymers. PF- $b$-PDEAEMA was prepared through atom transfer radical polymerization, as illustrated in Figure 1. By using solvents with different selectivities, namely, tetrahydrofuran (THF) and methanol $(\mathrm{MeOH})$, various aggregation morphologies of the block copolymers were observed in thin films and in a dilute solution through atomic force microscopy (AFM) and transmission electron microscopy (TEM), respectively. Furthermore, the photophysical properties of the block copolymers with various $\mathrm{MeOH}$ contents were characterized through UV-vis optical absorption and photoluminescence (PL) spectroscopy. In addition, their self-assembly behaviors are discussed in this paper.

\section{Materials and Methods}

2.1. Materials. 9,9-Dihexyl-2,7-dibromofluorene (PF, Aldrich, 97\%), 2-(diethylamino)ethyl methacrylate (DEAEMA, TCI, 98.5\%), ethyl ether anhydrous (TEDIA), copper(I) bromide (CuBr, Aldrich, 99.999\%), anhydrous THF (Echo), $\mathrm{N}, \mathrm{N}, \mathrm{N}^{\prime}, \mathrm{N}^{\prime}, \mathrm{N}^{\prime \prime}$-pentamethyldiethylenetriamine (PMDETA, Aldrich, 99\%), anhydrous $\mathrm{MeOH}$ (Mallinckrodt), n-hexane (TEDIA, 95\%), aluminum oxide (50-200 microns, Acros), and chloroform-d (99.8 atm\% D, Aldrich) were used as received to prepare the PF- $b$-PDEAEMA copolymers.

\subsection{Preparation of PF-Br Macroinitiator and PF- $b-P D E A E M A$.} First, a-\{4-[2-(2-bromo-2-methylpropoyloxy)methyl]phenyl\}bromo-poly[2,7-(9,9-dihexylfluorene)] (PF-Br) was synthesized through the Suzuki coupling reaction $[23,24]$. The resulting mixture was reacted with 2 -bromoisobutyryl bromide to obtain PF-Br, which was dried under vacuum overnight. PF- $b$-PDEAEMA (Figure 1) was prepared as follows: $79.2 \mathrm{mg}$ of $\mathrm{PF}-\mathrm{Br}(1 \mathrm{mmol}), 5.2 \mathrm{mg}$ of $\mathrm{CuBr}(2 \mathrm{mmol})$, and $1516 \mathrm{~mL}$ of DEAEMA $(500 \mathrm{mmol})$ were added to a dry round-bottom flask, and the system was maintained under vacuum for $10 \mathrm{~min}$. A solution of pentamethyldiethylenetriamine (PMDETA, $8 \mathrm{~mL}, 2 \mathrm{mmol}$ ) in $0.7 \mathrm{~mL}$ of anisole was added to the round-bottom flask under nitrogen atmosphere. The mixture was degassed three times, filled with nitrogen, stirred at ambient temperature for $30 \mathrm{~min}$, and immersed in an oil bath at $110^{\circ} \mathrm{C}$ for $24 \mathrm{~h}$. After cooling to room temperature, the mixture was passed through an $\mathrm{Al}_{2} \mathrm{O}_{3}$ column to remove the copper catalyst, precipitated into an excess amount of $\mathrm{n}$-hexane, and filtered; the product was dried under vacuum at $30^{\circ} \mathrm{C}$ to obtain $300 \mathrm{mg}$ of $\mathrm{PF}_{13^{-}}$ b-PDEAEMA ${ }_{100}$ yellow solid. ${ }^{1} \mathrm{H} \mathrm{NMR}\left(\mathrm{CDCl}_{3}, 300 \mathrm{MHz}\right)$ d (ppm): 0.78-0.98 (3 H, $\left.-\mathrm{CH}_{2} \mathrm{C}\left(\mathrm{CH}_{3}\right)-\right), 1.78-1.91(2 \mathrm{H}$, $\left.-\mathrm{CH}_{2} \mathrm{C}\left(\mathrm{CH}_{3}\right)-\right), 2.41-2.59\left(10 \mathrm{H},-\mathrm{N}\left(\mathrm{CH}_{2} \mathrm{CH}_{3}\right)_{2}\right), 2.69$ $\left.\mathrm{H},-\mathrm{OCH}_{2} \mathrm{CH}_{2} \mathrm{~N}\left(\mathrm{CH}_{2} \mathrm{CH}_{3}\right)_{2}\right), 3.98\left(2 \mathrm{H},-\mathrm{OCH}_{2} \mathrm{CH}_{2} \mathrm{~N}-\right.$ $\left.\left(\mathrm{CH}_{2} \mathrm{CH}_{3}\right)_{2}\right), 7.25-7.79(10 \mathrm{H}$, fluorene aromatic protons and phenyl end group) (Figure 2).

2.3. Preparation of PF-b-PDEAEMA Aggregates in Solution. $\mathrm{PF}_{13}-b$-PDEAEMA ${ }_{100}$ aggregates in solution were prepared by dissolving the polymer in THF and subsequently adding $\mathrm{MeOH}$ at volume ratios of $0 \%, 10 \%, 25 \%, 50 \%, 75 \%$, and $90 \%$; the polymer concentration was maintained at $0.1 \mathrm{wt} \%$ in the solution.

\section{Characterization}

Fourier transform infrared (FTIR) spectra of the prepared copolymers were obtained with a $\mathrm{KBr}$ pellet by using a PerkinElmer Spectrum spectrophotometer. ${ }^{1} \mathrm{H}-\mathrm{NMR}$ spectra of the prepared polymers were obtained using a JEOL EX400 spectrometer. Molecular weight was determined using a GPC instrument equipped with a refractive index detector (Schambeck SFD GmbH, model RI 2000), a Lab Alliance solvent delivery system, and a GPC column (PLgel $5 \mu \mathrm{m}$ mixed-C and D). Calibration was achieved by injecting a polystyrene standard diluted to $0.5 \mathrm{wt} \%$ in THF $(1 \mathrm{~mL} / \mathrm{min})$ at $40^{\circ} \mathrm{C}$. Thermal analyses were conducted on a differential scanning calorimeter (TA Instruments, TA Q20)-with a heating cycle from room temperature to $200^{\circ} \mathrm{C}$ at a heating 


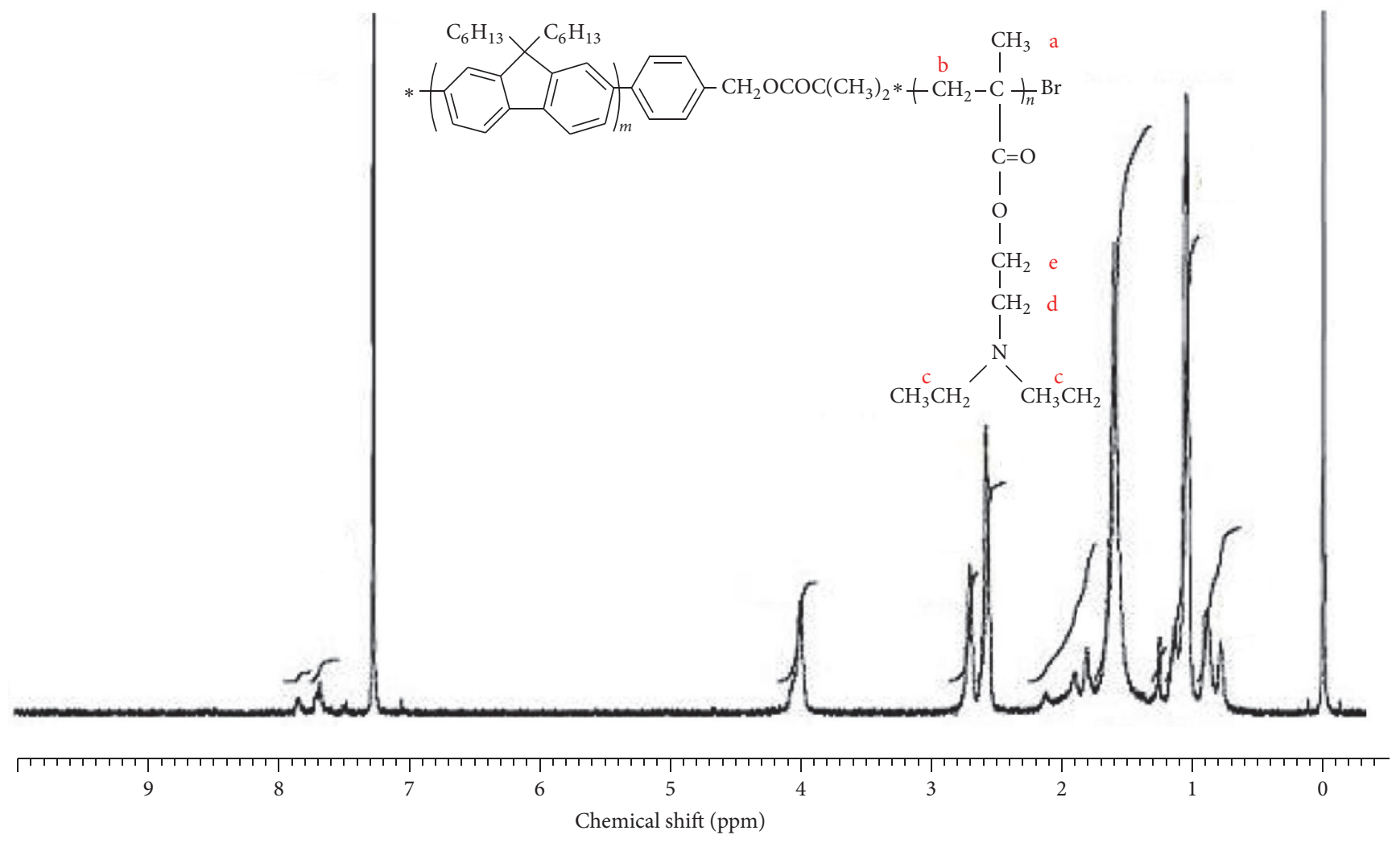

FIgURE 2: ${ }^{1}$ NMR spectra of rod-coil di-block $\mathrm{PF}_{13}-b$-PDEAEMA 100 .

rate of $20^{\circ} \mathrm{C} / \mathrm{min}$ - and a thermogravimetric analyzer (TA Instruments, TA Q50) with a heating range of room temperature to $900^{\circ} \mathrm{C}$ at $20^{\circ} \mathrm{C} / \mathrm{min}$.

The PF- $b$-PDEAEMA aggregate morphologies were characterized through TEM by using a JEOL 1210 operating at an acceleration voltage of $100 \mathrm{kV}$. A drop of the aggregate dispersion was cast onto a 200-mesh copper TEM grid deposited with carbon and dried under vacuum before imaging. The deuterated solvent used for obtaining the spectra was chloroform-d. The AFM data was obtained in the tapping mode on a Nanoscope DI III multimode instrument. UVvis spectra were obtained from polymer thin films prepared on glass through spin-coating at a speed of approximately $1000 \mathrm{rpm}$ by using a Jasco Model V-650 spectrometer. PL spectra were obtained using a Horiba Jobin Yvon Fluoromax4 Spectrofluorometer with $450 \mathrm{~nm}$ excitation wavelength.

\section{Results and Discussion}

Figure 3 shows the FTIR spectra of (a) PF-ph- $\mathrm{CH}_{2} \mathrm{OH}$ macroinitiator and (b) PF-Br macroinitiator. The broad characteristic band from 2980 to $2835 \mathrm{~cm}^{-1}$ was attributed to benzene. The peak at $1754 \mathrm{~cm}^{-1}$ is attributable to $\mathrm{C}=\mathrm{O}$, suggesting the hydroxyl group of replaced 2-bromoisobutyrate. Figure 3 is a plot of the gel permeation chromatographic analysis of the $\mathrm{PF}$ macroinitiator, where $\mathrm{PF}_{13}-b$-PDEAEMA $A_{100}$ was

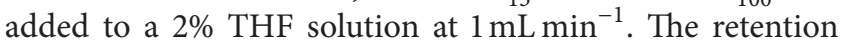
time of the PF macroinitiator reduced significantly with the addition of DMAEMA monomers, indicating the successful

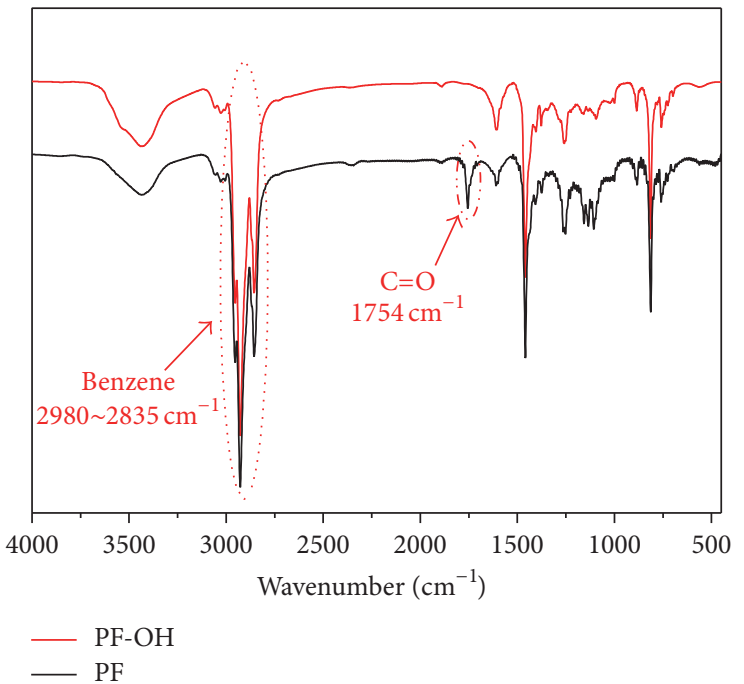

FIGURE 3: FTIR spectra of (a) PF-ph- $\mathrm{CH}_{2} \mathrm{OH}$ macroinitiator and (b) PF-Br macroinitiator.

polymerization of the DMAEMA monomer into the PF macroinitiator. In addition, the PDI of $\mathrm{PF}_{13}-b$-PDEAEMA 100 estimated through GPC ranged from 1.3 to 1.5 . The thermal properties of the PF macroinitiator and PF- $b$-PDEAEMA were estimated through thermogravimetric analysis (TGA; Figure 4). The thermal degradation temperatures of the PF macroinitiator and PF- $b$-PDEAEMA (weight loss of $5 \%$ ) were $400^{\circ} \mathrm{C}$ and $343^{\circ} \mathrm{C}$, respectively, suggesting that the 


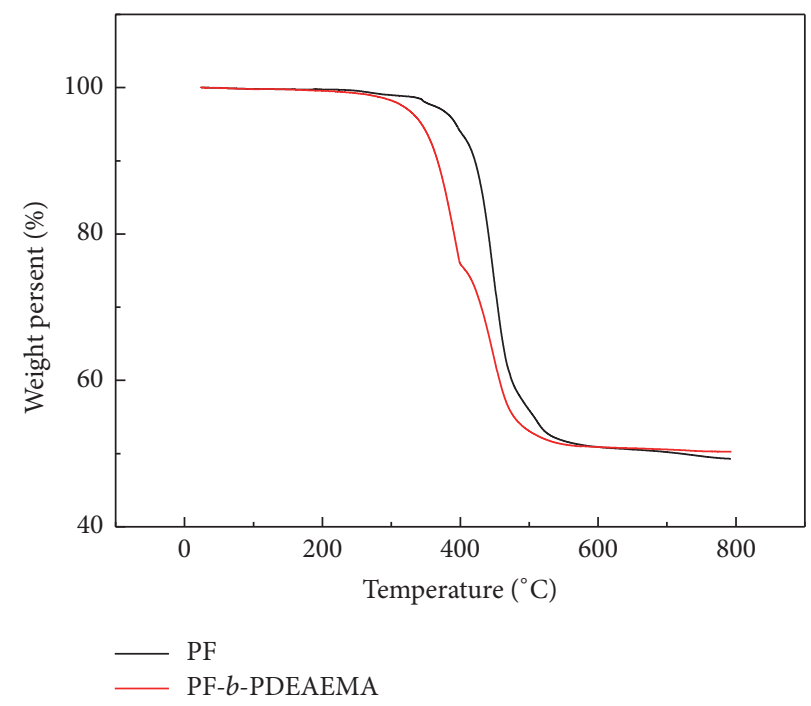

Figure 4: TGA spectra of (a) PF-Br macroinitiator and (b) $\mathrm{PF}_{13}-b$-PDEAEMA 100 .

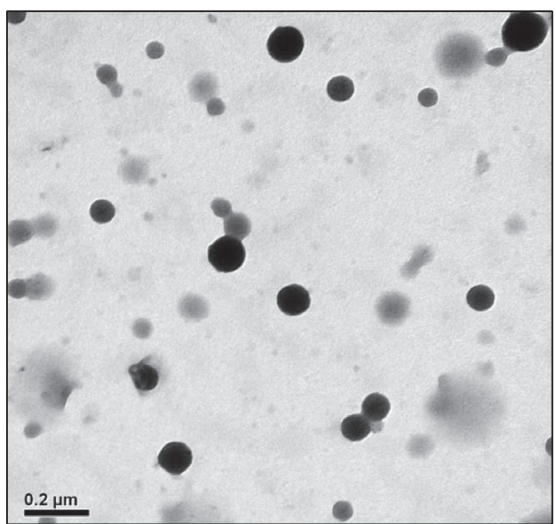

(a)

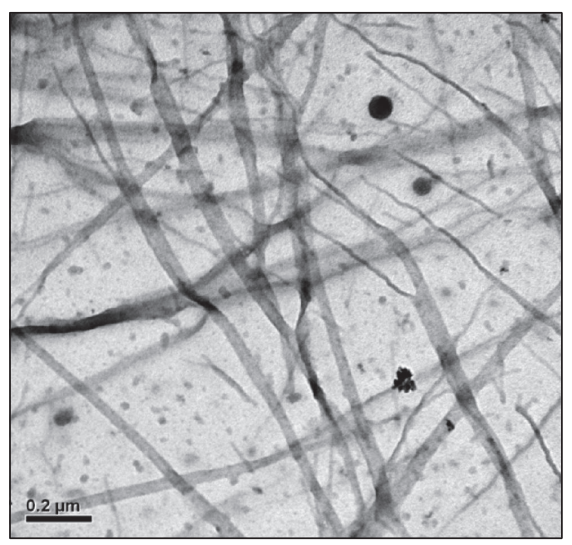

(d)

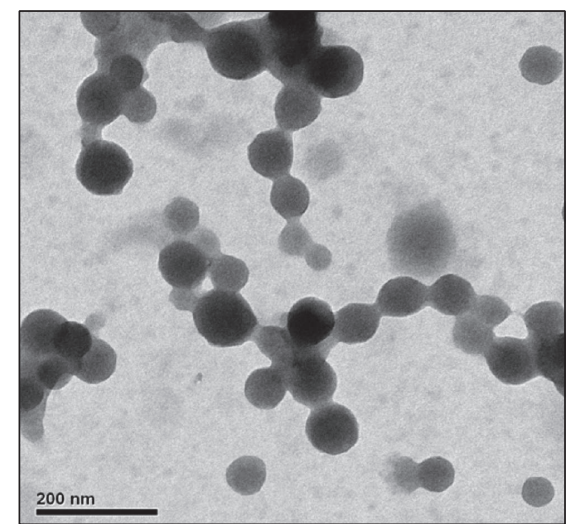

(b)

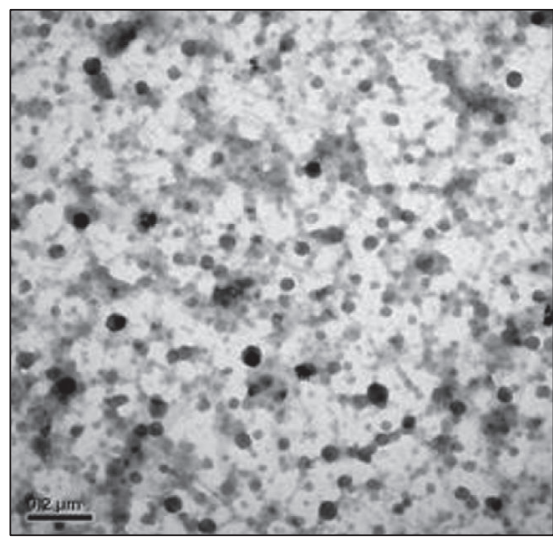

(e)

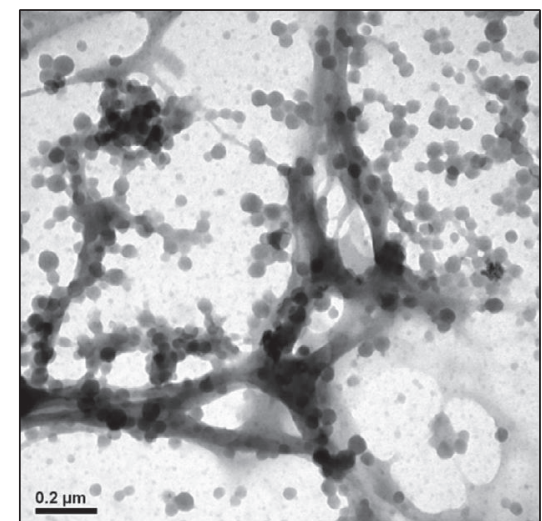

(c)

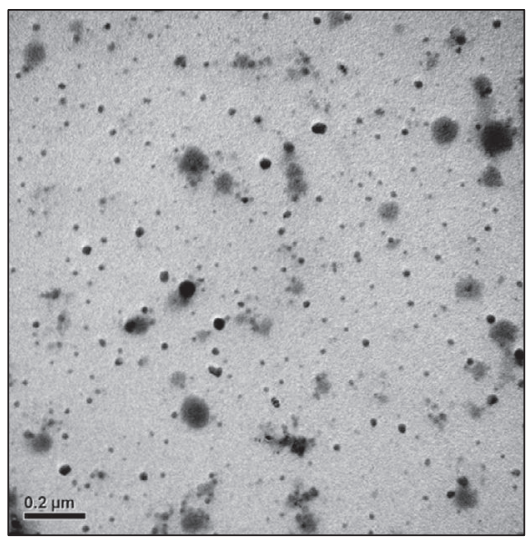

(f)

Figure 5: TEM images of $\mathrm{PF}_{13}-b$-PDEAEMA 100 aggregates in dilute MeOH/THF solution with MeOH content of (a) 0, (b) 10, (c) 25, (d) 50, (e) 75 , and (f) $90 \mathrm{vol} \%$, respectively.

thermal stability of PF decreased with the incorporation of PDEAEMA.

The micellar aggregation of $\mathrm{PF}_{13}-b$-PDEAEMA 100 for various selectivities of $\mathrm{THF} / \mathrm{MeOH}$ was investigated through TEM. THF is a good solvent for PF but a selective solvent for PDEAEMA. By contrast, $\mathrm{MeOH}$ is a good solvent for PDEAEMA but a selective solvent for PF. Figure 5 shows the aggregation behaviors of PF- $b$-PDEAEMA in a mixed $\mathrm{THF} / \mathrm{MeOH}$ solution for $\mathrm{MeOH}$ contents of $0-90 \mathrm{vol} \%$. Spherical micelles were observed in pure THF solution 


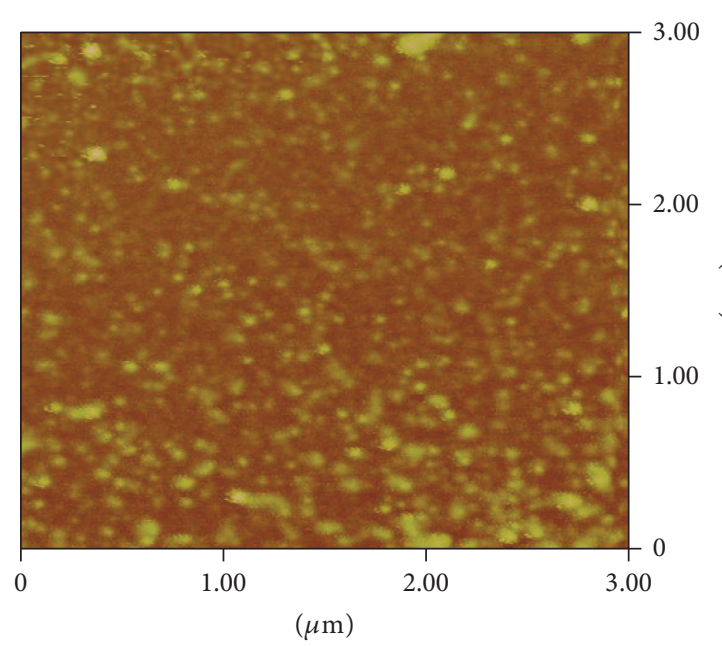

(a)

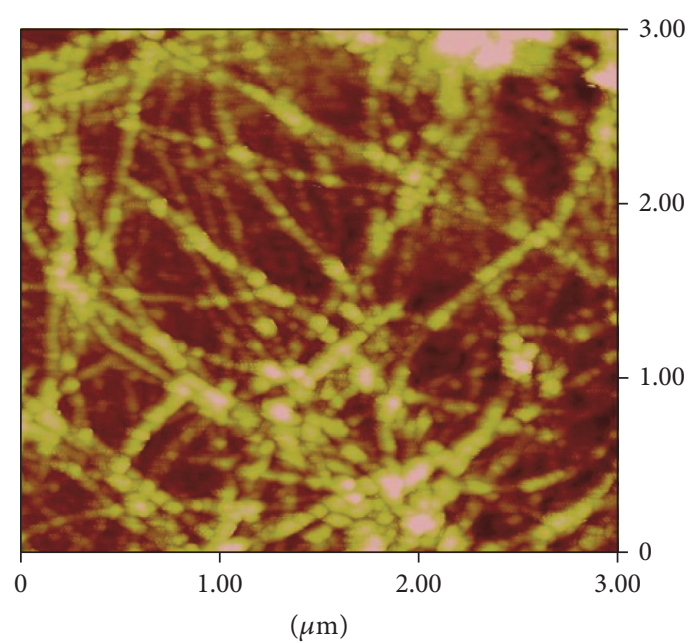

(c)

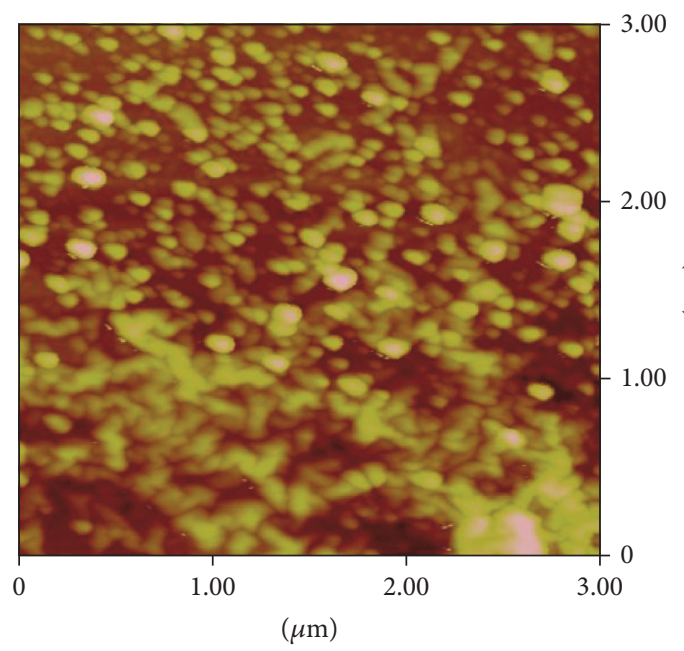

(e)

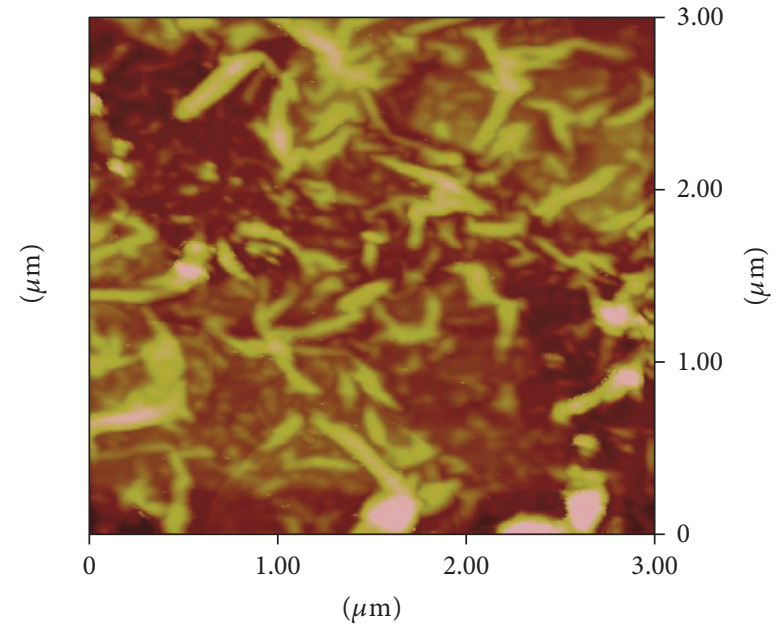

(b)

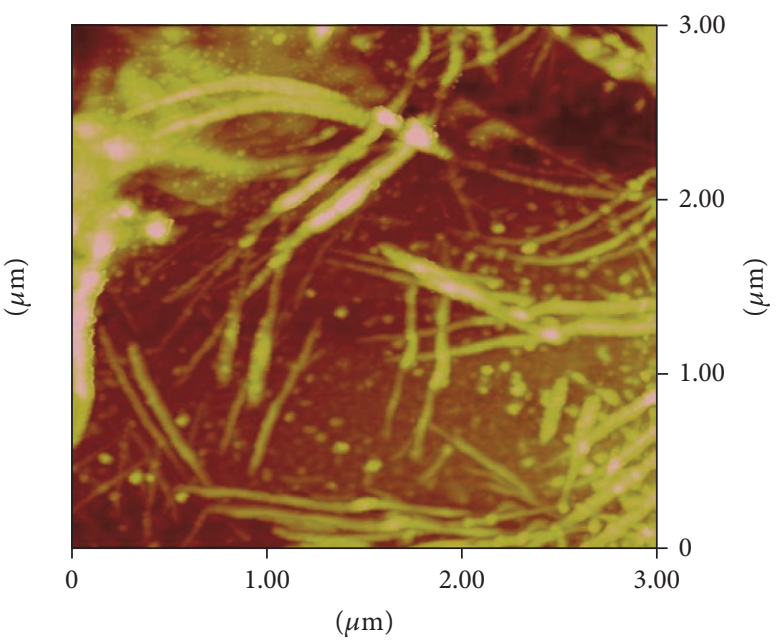

(d)

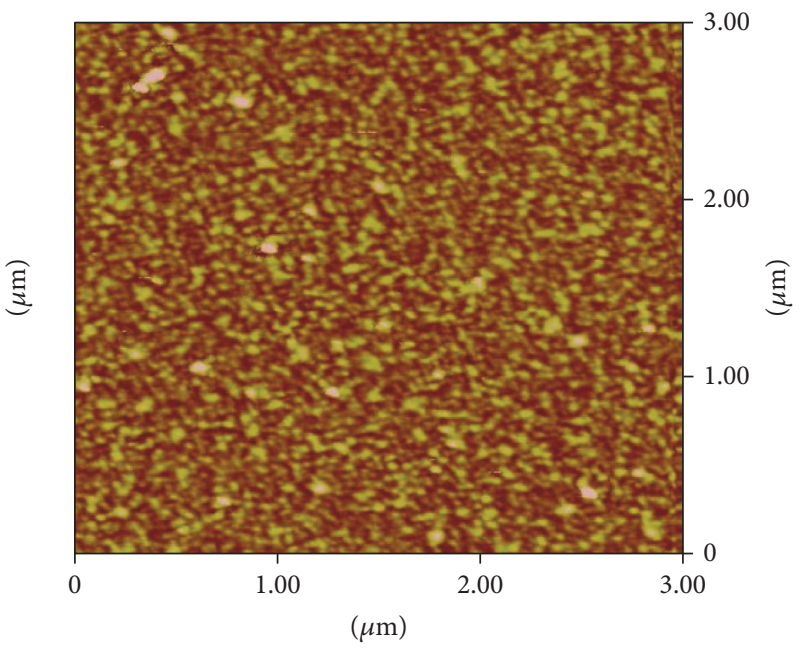

(f)

Figure 6: AFM images of $\mathrm{PF}_{13}-b$-PDEAEMA 100 aggregates in dilute MeOH/THF solution with MeOH content of (a) 0, (b) 10, (c) 25, (d) 50, (e) 75 , and (f) $90 \mathrm{vol} \%$, respectively. 
(Figure 5(a)). THF acted as a good solvent for PF but a poor solvent for PDEAEMA, leading to the extension of PF chains as the corona and the aggregation of PDEAEMA as the core. When the $\mathrm{MeOH}$ content was increased to $10 \mathrm{vol} \%$, the spherical micelles preferentially aggregated as a bundle with worm-like morphology, because this morphology efficiently reduces the high interfacial energy of PF. When the $\mathrm{MeOH}$ content was increased to $25 \mathrm{vol} \%$, the worm-like micelles acted as dendritic structures, and the size of the micelles decreased. On increasing the $\mathrm{MeOH}$ content to $50 \%$, ribbon-like micelles were observed (Figure 5(d)), presumably because, for a THF: $\mathrm{MeOH}$ ratio of $50: 50, \mathrm{MeOH}$ increases the interfacial energy between the PF corona and the PDEAEMA core, leading to a ribbon-like morphology that reduces the increased interfacial energy. When the $\mathrm{MeOH}$ content exceeded that of THF, the ribbon-like micelles transformed to spherical aggregates, presumably because the mixed solution consisting of a large amount of $\mathrm{MeOH}$ causes the stretching of hydrophilic PDEAEMA and PF aggregation. Therefore, the micelles comprising PDEAEMA cores and PF coronas preferentially inverted to form micelles comprising $\mathrm{PF}$ cores and PDEAEMA coronas when the $\mathrm{MeOH}$ content was high (Figures 5(e) and 5(f)). These observations suggest that solvent selectivity is a critical factor influencing the aggregation morphology of di-block copolymers in solution.

The aggregation morphologies of $\mathrm{PF}_{13}-b$-PDEAEMA 100 in the solid state were also investigated through AFM. Figure 6 presents AFM images of thin films of PF- $b$-PDEAEMA obtained from dilute $\mathrm{THF} / \mathrm{MeOH}$ solutions with various $\mathrm{MeOH}$ contents. At high $\mathrm{MeOH}$ content, the AFM images of $\mathrm{PF}_{13}-b$-PDEAEMA 100 revealed spheres and worm-like micelles and ribbon-like morphologies, which are consistent with the TEM images. These observations suggest that the morphological transformation of PF- $b$-PDEAEMA induced by solvent selectivity can occur in the solid and solution states.

Figure 7 shows the UV and PL spectra of $\mathrm{PF}_{13}-b$ PDEAEMA $_{100}$ in a dilute THF/MeOH solution with $\mathrm{MeOH}$ content ranging from 0 to $90 \mathrm{vol} \%$. The maximum absorption wavelength of $\mathrm{PF}_{13}-b$-PDEAEMA ${ }_{100}$ in pure THF solution was $370 \mathrm{~nm}$. On increasing the $\mathrm{MeOH}$ content to $75 \mathrm{vol} \%$, the maximum absorption wavelength of $\mathrm{PF}_{13}$ - $b$-PDEAEMA 100 exhibited a hypsochromic shift from 370 to $363 \mathrm{~nm}$, presumably because the aggregation induced by the selective solvent makes the PF segments less coplanar, leading to a decrease in the conjugated length [12]. This hypsochromic shift is commonly attributed to H-type aggregation, in which the conjugation segments are oriented in parallel. In the PL spectra, the small conjugation length similarly caused fluorescence quenching and lower structure emission of $\mathrm{PF}_{13}-b$-PDEAEMA ${ }_{100}[9,12]$. Thus, the fluorescence intensity of $\mathrm{PF}_{13}-b$-PDEAEMA 100 decreased significantly with an increase in the amount of the selective solvent. The hypsochromic shift and quenching of the emission spectra indicate a typical $\mathrm{H}$-type stacking of $\mathrm{PF}_{13}-b$-PDEAEMA 100 in the $\mathrm{MeOH} / \mathrm{THF}$ solution. Moreover, the PL quantum yields of $\mathrm{PF}_{13}$ - $b$-PDEAEMA 100 decreased from $73 \%$ in pure THF solution to $62,60,57,48$, and $43 \%$ in $10 \%, 25 \%, 50 \%$, $75 \%$, and 90 vol.\% mixed $\mathrm{MeOH} / \mathrm{THF}$ solvents, respectively.
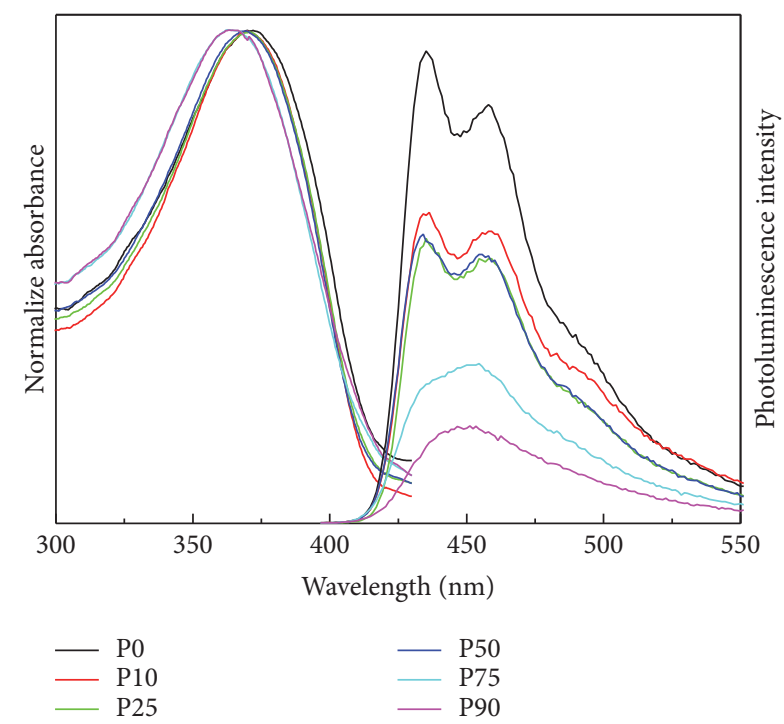

FIgUre 7: Optical UV and PL spectra of PF- $b$-PDEAEMA in dilute $\mathrm{MeOH} / \mathrm{THF}$ solution with $\mathrm{MeOH}$ content ranging from 0 to 90 vol\%.

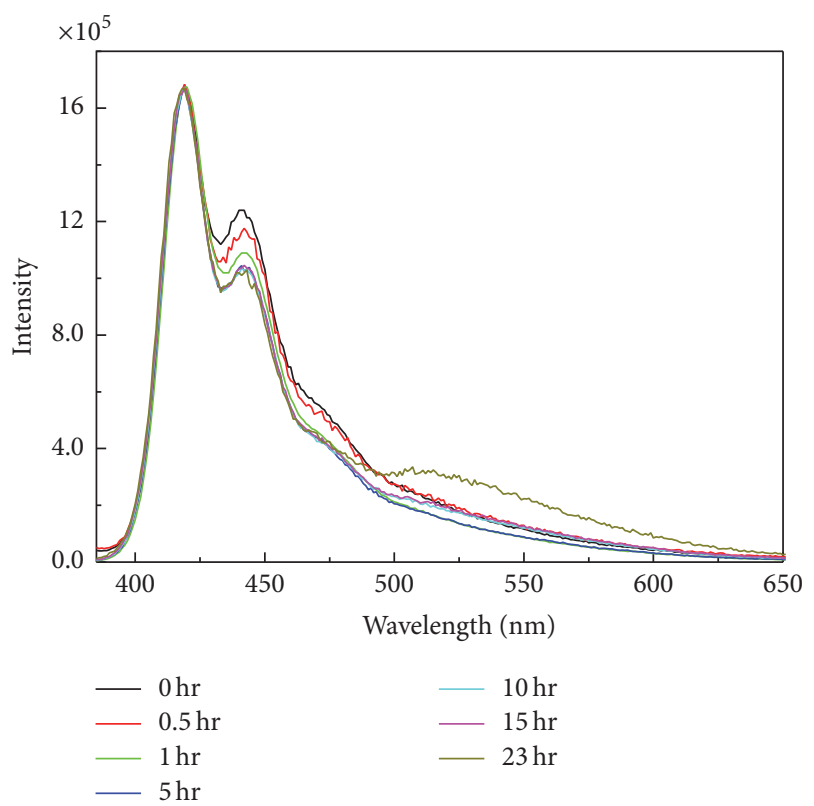

FIGURE 8: PL spectra of PF-Br macroinitiator thin film annealed for different durations at $120^{\circ} \mathrm{C}$.

The degree of hypsochromic shift and the decrease in PL quantum yield increased as the length of PDEAEMA coils and the content of the poor solvent increased, indicating that photophysical properties can be manipulated by the coil length of the PDEAEMA block and the selectivity of the solvents.

Figure 8 shows the thin-film PL spectra of PF-Br macroinitiator annealed for a long duration at $120^{\circ} \mathrm{C}$. The PL emission of PF-Br macroinitiator varied only slightly with annealing time, suggesting the high thermal stability of PF$\mathrm{Br}$ macroinitiator compared with the $\mathrm{PF}-\mathrm{Br}$ macroinitiator. 


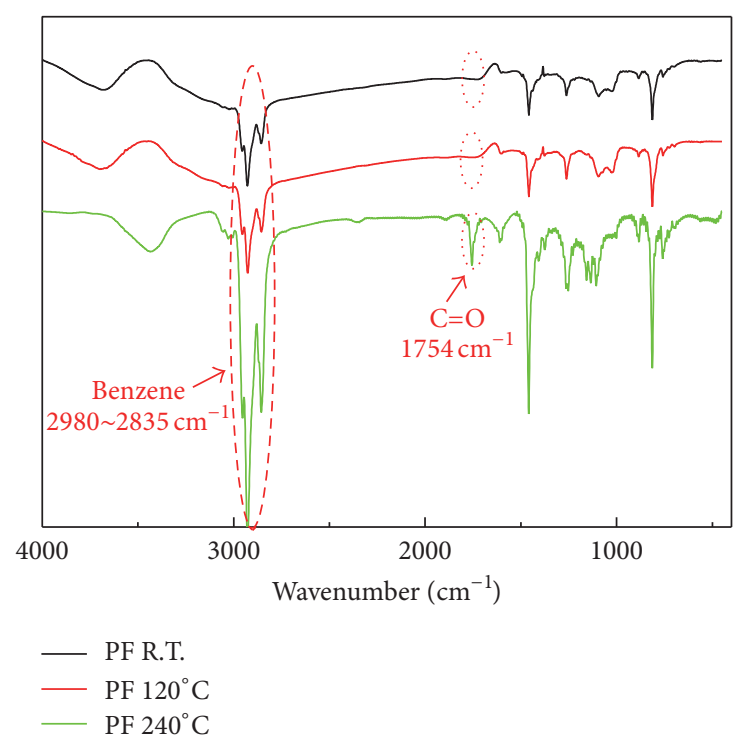

FIGURE 9: FTIR spectra of PF-Br macroinitiator thin film annealed at R.T., $120^{\circ} \mathrm{C}$, and $240^{\circ} \mathrm{C}$.

During annealing, enhanced emission in the $500-600 \mathrm{~nm}$ range is commonly attributed to the formation of fluorenone or excimers $[25,26]$. To investigate the enhanced PL emission, we employed infrared spectroscopy to determine the thermal stability of the PF-Br macroinitiator (Figure 9). After hightemperature annealing for a long duration, the peak of the $\mathrm{PF}-\mathrm{Br}$ macroinitiator at $1754 \mathrm{~cm}^{-1}$ increased remarkably; this is attributable to the appearance of fluorenone. Therefore, the enhanced emission of $\mathrm{PF}_{13}-b$-PDEAEMA ${ }_{100}$ in the 500$600 \mathrm{~nm}$ range is attributable primarily to the formation of fluorenone. In comparison with the PF-Br macroinitiator, as shown in our previous study, $\mathrm{PF}_{13}$ - $b$-PDEAEMA ${ }_{100}$ exhibited higher thermal stability because of the di-block architecture, which can suppress the formation of fluorenone during annealing.

\section{Conclusion}

The morphologies, synthesis, and photophysical characterizations of amphiphilic rod-coil $\mathrm{PF}_{13}-b$-PDEAEMA 100 were demonstrated. A variety of morphologies, including spheres, worm-like micelles, ribbon-like micelles and inverted spheres, were obtained after tuning the selectivity of mixed THF/MeOH solvents. The morphological transformation caused significant variations in the absorption, fluorescence spectra, and fluorescence quenching of rod-coil copolymers. The hypsochromic shifting and PL quenching of $\mathrm{PF}_{13}-b$-PDEAEMA ${ }_{100}$ were influenced largely by the selective solvent content $(\mathrm{MeOH})$, presumably because of $\mathrm{H}$-type aggregation. Furthermore, the di-block structure of $\mathrm{PF}_{13}-b$ PDEAEMA $_{100}$ suppressed the formation of fluorenone and afforded higher thermal stability in comparison with $\mathrm{PF}-\mathrm{Br}$ macroinitiator. The results of the present study suggest the effect of solvent selectivity on the photophysical properties of rod-coil block copolymers. The PL quantum yields of $\mathrm{PF}_{13}-b$ PDEAEMA $_{100}$ decreased from $73 \%$ in pure THF solution to
$62,60,57,48$, and $43 \%$ in $10 \%, 25 \%, 50 \%, 75 \%$, and 90 vol. $\%$ mixed $\mathrm{MeOH} / \mathrm{THF}$ solvents, respectively.

\section{Competing Interests}

The authors declare that they have no competing interests.

\section{Acknowledgments}

The financial support provided by the National Science Council of Taiwan (Project no. MOST 104-2221-E-131-025MY3) is greatly appreciated.

\section{References}

[1] F. Wu, Y. S. Song, Z. Y. Zhao et al., "Preparation and selfassembly of supramolecular coil-rod-coil triblock copolymer PPO-dsDNA-PPO," Macromolecules, vol. 48, no. 20, pp. 75507556, 2015.

[2] Y. F. Tu, Z. C. Ji, X. M. Yang, X. H. Wan, and Q.-F. Zhou, "Supramolecular chemistry in the formation of self-assembled nanostructures from a high-molecular-weight rod-coil block copolymer," Macromolecular Rapid Communications, vol. 35, no. 20, pp. 1795-1800, 2014.

[3] V. R. de la Rosa, W. M. Nau, and R. Hoogenboom, "Thermoresponsive interplay of water insoluble poly(2-alkyl-2oxazoline)s composition and supramolecular host-guest interactions," International Journal of Molecular Sciences, vol. 16, no. 4, pp. 7428-7444, 2015.

[4] A. Hirao, M. Hayashi, S. Loykulnant et al., "Precise syntheses of chain-multi-functionalized polymers, star-branched polymers, star-linear block polymers, densely branched polymers, and dendritic branched polymers based on iterative approach using functionalized 1,1-diphenylethylene derivatives," Progress in Polymer Science, vol. 30, no. 2, pp. 111-182, 2005.

[5] M. Lee, B.-K. Cho, and W.-C. Zin, "Supramolecular structures from rod-coil block copolymers," Chemical Reviews, vol. 101, no. 12, pp. 3869-3892, 2001.

[6] F. J. M. Hoeben, P. Jonkheijm, E. W. Meijer, and A. P. H. J. Schenning, "About supramolecular assemblies of $\pi$-conjugated systems," Chemical Reviews, vol. 105, no. 4, pp. 1491-1546, 2005.

[7] J. F. Reuther, D. A. Siriwardane, R. Campos, and B. M. Novak, "Solvent tunable self-assembly of amphiphilic rod-coil block copolymers with chiral, helical polycarbodiimide segments: polymeric nanostructures with variable shapes and sizes," Macromolecules, vol. 48, no. 19, pp. 6890-6899, 2015.

[8] K.-L. Zhong, Z. S. Wang, Y. R. Liang, T. Chen, B. Z. Yin, and L. Y. Jin, "Ordered nanostructures from self-assembly of rodcoil oligomers with n-shaped rod and dendritic poly(ethylene oxide) coil segment," Supramolecular Chemistry, vol. 26, no. 1012, pp. 729-735, 2014.

[9] S.-T. Lin, Y.-C. Tung, and W.-C. Chen, "Synthesis, structures and multifunctional sensory properties of poly[2,7-(9,9dihexylfluorene)]-block-poly[2-(dimethylamino)ethyl methacrylate] rod-coil diblock copolymers," Journal of Materials Chemistry, vol. 18, no. 33, pp. 3985-3992, 2008.

[10] M. Moshonov and G. L. Frey, "Directing hybrid structures by combining self-assembly of functional block copolymers and atomic layer deposition: a demonstration on hybrid photovoltaics," Langmuir, vol. 31, no. 46, pp. 12762-12769, 2015. 
[11] V. R. de la Rosa and R. Hoogenboom, "Solution polymeric optical temperature sensors with long-term memory function powered by supramolecular chemistry," Chemistry-A European Journal, vol. 21, no. 3, pp. 1302-1311, 2015.

[12] C.-H. Lin, Y.-C. Tung, J. Ruokolainen, R. Mezzenga, and W.-C. Chen, "Poly[2,7-(9,9-dihexylfluorene)]-block-poly(2-vinylpyridine) rod-coil and coil-rod-coil block copolymers: synthesis, morphology and photophysical properties in methanol/THF mixed solvents," Macromolecules, vol. 41, no. 22, pp. 8759-8769, 2008.

[13] S. Lu, Q.-L. Fan, S.-Y. Liu, S.-J. Chua, and W. Huang, "Synthesis of conjugated-acidic block copolymers by atom transfer radical polymerization," Macromolecules, vol. 35 , no. 27, pp. 98759881, 2002.

[14] S. Lu, Q.-L. Fan, S.-J. Chua, and W. Huang, "Synthesis of conjugated-ionic block copolymers by controlled radical polymerization," Macromolecules, vol. 36, no. 2, pp. 304-310, 2003.

[15] S. Lu, T. X. Liu, L. Ke, D.-G. Ma, S.-J. Chua, and W. Huang, "Polyfluorene-based light-emitting rod-coil block copolymers," Macromolecules, vol. 38, no. 20, pp. 8494-8502, 2005.

[16] S. A. Jenekhe and X. L. Chen, "Self-assembled aggregates of rod-coil block copolymers and their solubilization and encapsulation of fullerenes," Science, vol. 279, no. 5358, pp. 1903-1907, 1998.

[17] W.-C. Wu, C.-L. Liu, and W.-C. Chen, "Synthesis and characterization of new fluorene-acceptor alternating and random copolymers for light-emitting applications," Polymer, vol. 47, no. 2, pp. 527-538, 2006.

[18] Y.-C. Tung, W.-C. Wu, and W.-C. Chen, "Morphological transformation and photophysical properties of rod-coil poly[2,7(9,9- Dihexylfluorene)]-block-poly(acrylic acid) in solution," Macromolecular Rapid Communications, vol. 27, no. 21, pp. 1838-1844, 2006.

[19] Y.-C. Tung and W.-C. Chen, "Poly[2,7-(9,9-dihexylfluorene)]block-poly[3-(trimethoxysilyl)propyl methacrylate] (PF-bPTMSPMA) rod-coil block copolymers: synthesis, morphology and photophysical properties in mixed solvents," Reactive \& Functional Polymers, vol. 69, no. 7, pp. 507-518, 2009.

[20] W. Lee, J.-S. Kim, H. J. Kim et al., "Graft architectured rodcoil copolymers based on alternating conjugated backbone: morphological and optical properties," Macromolecules, vol. 48, no. 16, pp. 5563-5569, 2015.

[21] K. Saito, T. Isono, H.-S. Sun, T. Kakuchi, W.-C. Chen, and T. Satoh, "Rod-coil type miktoarm star copolymers consisting of polyfluorene and polylactide: precise synthesis and structuremorphology relationship," Polymer Chemistry, vol. 6, no. 39, pp. 6959-6972, 2015.

[22] A. Muñoz-Bonilla, M. Fernández-García, and D. M. Haddleton, "Synthesis and aqueous solution properties of stimuliresponsive triblock copolymers," Soft Matter, vol. 3, no. 6, pp. 725-731, 2007.

[23] X. Gao, P. Lu, and Y. G. Ma, "Ultrasound-assisted Suzuki coupling reaction for rapid synthesis of polydihexylfluorene," Polymer, vol. 55, no. 14, pp. 3083-3086, 2014.

[24] Y. Yao, J. Gao, F. Bao, S. Jiang, X. Zhang, and R. Ma, “Covalent functionalization of graphene with polythiophene through a Suzuki coupling reaction," RSC Advances, vol. 5, no. 53, pp. 42754-42761, 2015.

[25] D. Marsitzky, M. Klapper, and K. Müllen, "End-functionalization of poly(2,7-fluorene): a key step toward novel luminescent rod-coil block copolymers," Macromolecules, vol. 32, no. 25, pp. 8685-8688, 1999.
[26] Y. K. Kwon, H. S. Kim, H. J. Kim et al., "Reduced excimer formation in polyfluorenes by introducing coil-like poly[penta(ethylene glycol) methyl ether methacrylate] block segments," Macromolecules, vol. 42, no. 3, pp. 887-891, 2009. 

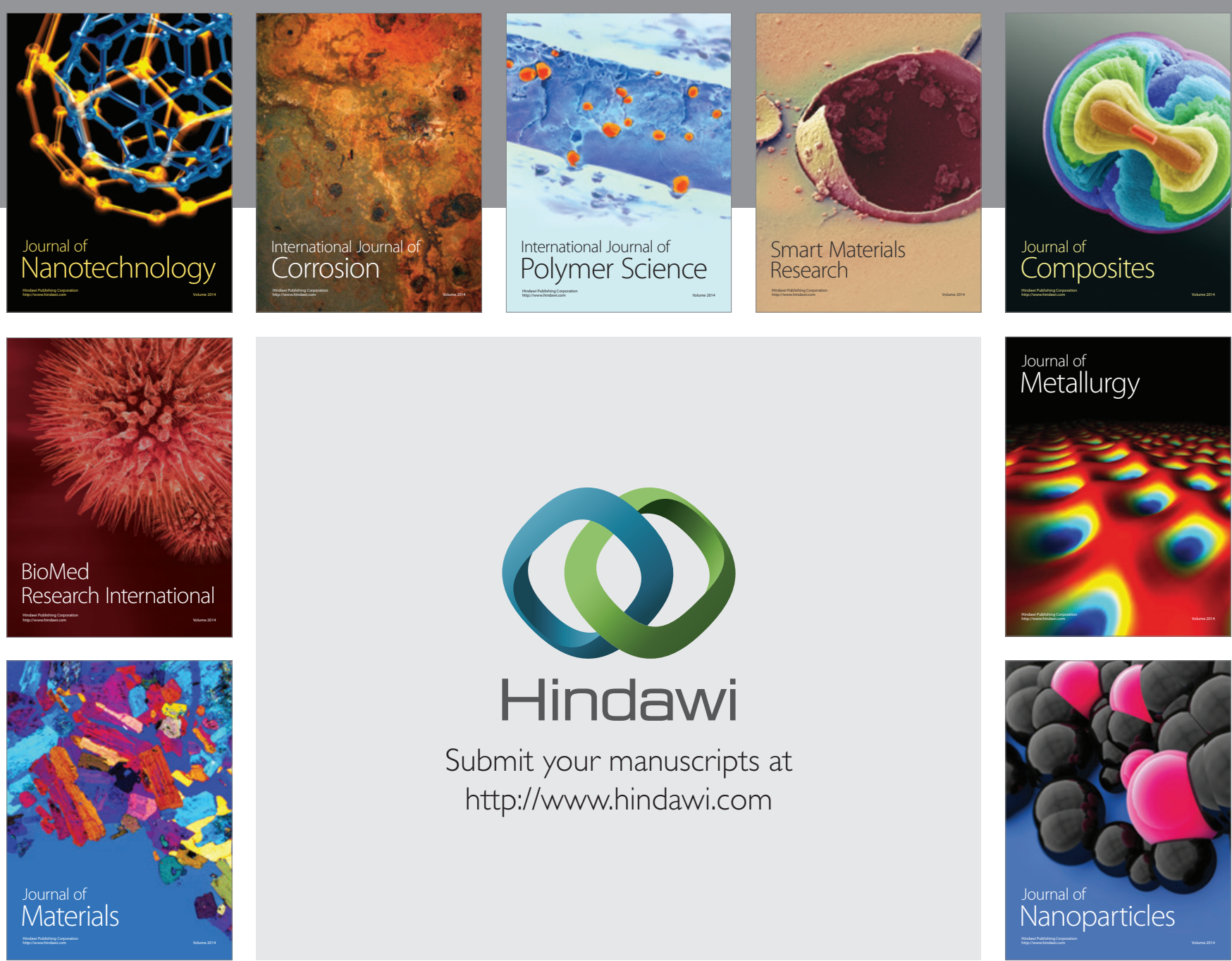

\section{Hindawi}

Submit your manuscripts at

http://www.hindawi.com

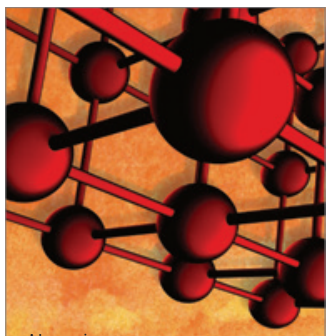

Materials Science and Engineering
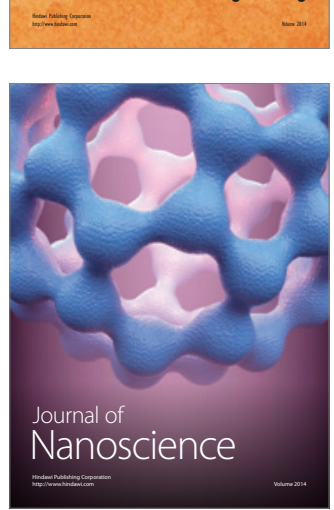
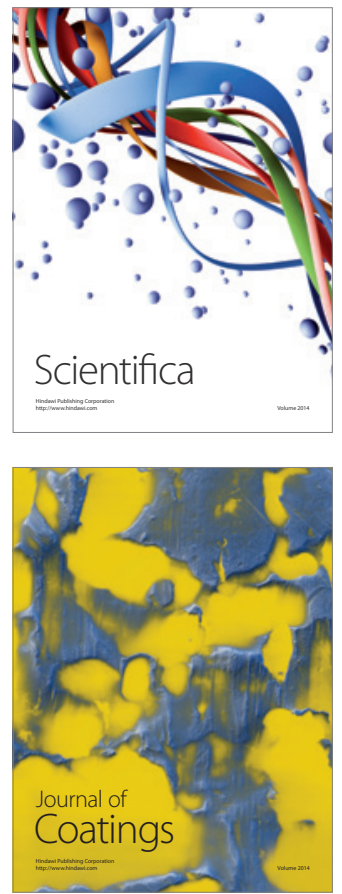
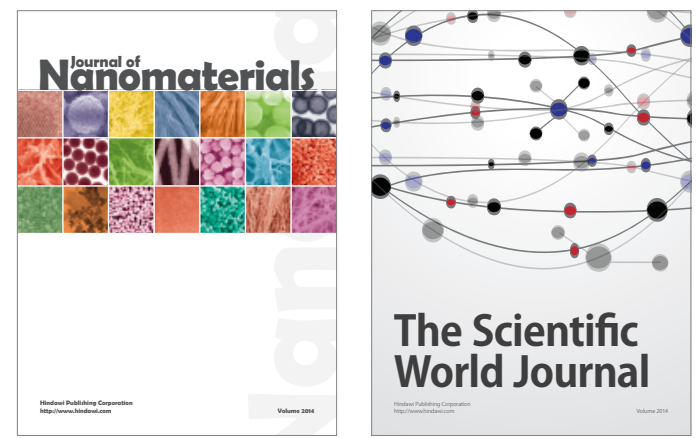

The Scientific World Journal
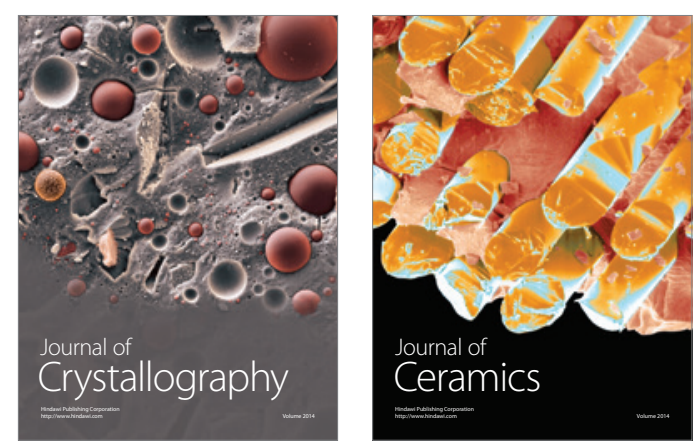
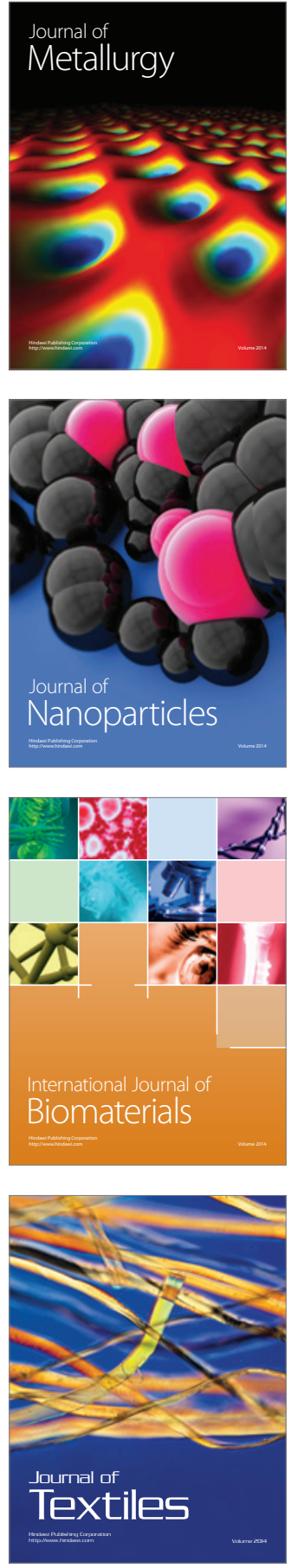